\title{
Non-descent vaginal hysterectomy in previous cesarean section: a retrospective study
}

\author{
K. J. Jacob, Divya M. B.*
}

Department of Obstetrics and Gynecology, Government Medical College, Thrissur, Kerala, India

Received: 19 May 2020

Accepted: 26 June 2020

\section{*Correspondence:}

Dr. Divya M. B.,

E-mail: divyambbs25@gmail.com

Copyright: (C) the author(s), publisher and licensee Medip Academy. This is an open-access article distributed under the terms of the Creative Commons Attribution Non-Commercial License, which permits unrestricted non-commercial use, distribution, and reproduction in any medium, provided the original work is properly cited.

\begin{abstract}
Background: Non-descent vaginal hysterectomy (NDVH) is removal of uterus through vagina in non-prolapsed uterus. As there is an increase in caesarean section, hysterectomy in women with previous caesarean section is also increasing. The objective of this study is to assess the feasibility and safety of non-descent vaginal hysterectomy in patients with previous caesarean section.

Methods: This is a retrospective study conducted in the department of obstetrics and gynecology, Government Medical College, Thrissur from January 2017 to December 2018. Non-descent vaginal hysterectomy in 24women with previous caesarean section was studied. Details regarding age, parity, number of caesarean sections, indication of surgery, intraoperative and postoperative complications were evaluated.

Results: All 24 women underwent non-descent vaginal hysterectomy successfully. 10 women (41.7\%) were between 46-49 years. Commonest indication of hysterectomy was fibroid uterus $(41.7 \%)$ and most common complaint was heavy menstrual bleeding (79\%). There was bladder injury in one woman with history of previous 2 caesarean section. 3 women developed UTI in postoperative period.

Conclusions: Vaginal hysterectomy is associated with lower complications and more rapid recovery. A successful NDVH in previous caesarean section depends on the expertise and experience of the surgeon. NDVH in previous caesarean is safe in expert hands.
\end{abstract}

Keywords: Caesarean section, Fibroid uterus, Heavy menstrual bleeding, Non-descent vaginal hysterectomy, Urinary tract infection

\section{INTRODUCTION}

Hysterectomy is the commonest major surgical procedure performed in gynaecology. ${ }^{1}$ Hysterectomy can be done by abdominally, vaginally, laparoscopically or with robotic assistance. Abdominal hysterectomy is more popular and is associated with more complications when compared with vaginal hysterectomy. Vaginal route hysterectomy is best method as it is scar less, with less morbidity, less blood loss, less operating time and less postoperative complications. ${ }^{2}$ Non-descent vaginal hysterectomy is removal of uterus through vagina in nonprolapsed uterus. As there is an increase in caesarean section, hysterectomy in women with previous caesarean section is also increasing. The objective of this study is to assess the feasibility of non-descent vaginal hysterectomy in patients with previous caesarean section and also to study the intraoperative and postoperative complications.

\section{METHODS}

This is a retrospective study conducted in the department of obstetrics and gynecology, Government Medical College, Thrissur, from January 2017 to December 2018. A total 24 women with history of previous caesarean section underwent non-descent vaginal hysterectomy. 


\section{Inclusion criteria}

- Women with history of previous 1 or more CS who underwent non-descent vaginal hysterectomy.

\section{Exclusion criteria}

- Uterine size more than 20 weeks

- Women with prolapsed uterus.

Consent for conversion to abdominal hysterectomy if needed was taken. Preoperatively, all cases were assessed regarding the size of the uterus, mobility and regarding the vaginal accessibility. All patients had their routine investigations done, including Pap smear and ultrasound pelvis before surgery. All cases were done under spinal anaesthesia.

\section{Procedure}

All cases were done under spinal anaesthesia. The anterior lip and posterior lip of cervix were held with long Allis forceps. Saline adrenaline infiltration (1:200000) was done. This provides a good surgical plane for dissection of bladder with minimal blood loss. Circular incision was made around the cervix, pubovesico-cervical ligament was cut and bladder mobilized upwards. At the site of previous scar, bladder was sharply dissected out and then carefully mobilized upwards by speculum, till the anterior peritoneum covering the uterus is visible as glistening white. The anterior peritoneum is opened. Posterior pouch was opened subsequently. In case of any difficulty in opening uterovesical fold, then the POD opened first. Uterosacral and cardinal ligaments were clamped, cut and ligated. Bilateral clamping of uterine vessels was done. After clamping and ligating uterine arteries on both sides, if the size of uterus was big, then morcellation, debulking and bisection were done to facilitate vaginal delivery of uterus. After delivering the uterus in the vagina, hysterectomy was completed by applying bilateral cornual clamps, cutting and ligating it properly. Ovarian removal was done in required cases by clamping infundibulopelvic ligament. All the pedicles were rechecked for any bleeding or oozing and vault closed meticulously. Foley's catheter was kept in all patients for 24 hours. All patients received prophylactic antibiotics.

Details regarding age, parity, number of caesarean sections, indication of surgery, uterine size, intraoperative and postoperative complications were evaluated. Details collected from case sheets. Descriptive data presented as number and percentages. Data was coded and entered into excel sheets and analysed using Epiinfo software.

\section{RESULTS}

All 24 underwent non-descent vaginal hysterectomy successfully. Majority of women, 10 (41.7\%) were between 46-49 years and only two women were there between age group 35-39 years (Table 1). 18 women (75\%) were para 2 (Table 2), among which 15 women had previous 2 CS. 9 women had previous 1 CS (Figure 1).

Table 1: Age distribution.

\begin{tabular}{|lll|}
\hline Age (years) & Number & Percentage \\
\hline 35-39 years & 2 & $8.3 \%$ \\
\hline 40-45 years & 7 & $29.2 \%$ \\
\hline 46-49 years & 10 & $41.7 \%$ \\
\hline $50-55$ years & 5 & $20.8 \%$ \\
\hline Total & 24 & $100 \%$ \\
\hline
\end{tabular}

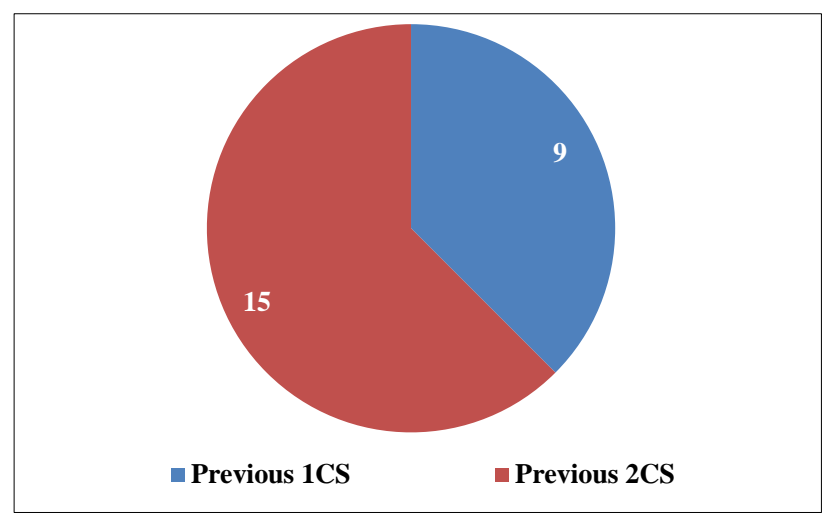

Figure 1: Number of previous CS.

Table 2: Distribution according to parity.

\begin{tabular}{|lll|}
\hline Parity & Number & Percentage \\
\hline 1 & 5 & $20.8 \%$ \\
\hline 2 & 18 & $75 \%$ \\
\hline 3 & 1 & $4.2 \%$ \\
\hline
\end{tabular}

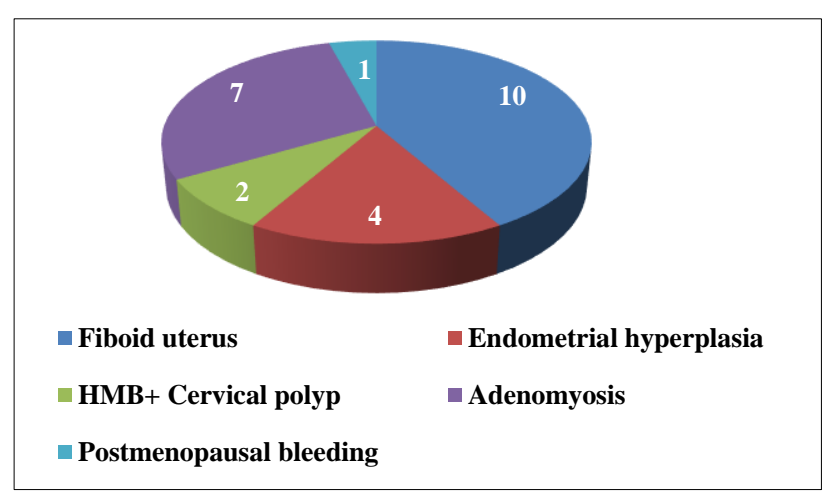

Figure 2: Indications for NDVH.

Table 3: Distribution of uterine size.

\begin{tabular}{|lll|}
\hline Uterine size & Number & Percentage \\
\hline Normal size & 2 & $8.3 \%$ \\
\hline Bulky (8 weeks) & 3 & $12.5 \%$ \\
\hline 12 weeks & 15 & $62.5 \%$ \\
\hline 14-16 weeks & 4 & $16.7 \%$ \\
\hline
\end{tabular}


Commonest indication for hysterectomy was fibroid uterus $(41.7 \%)$ and other indications were adenomyosis, postmenopausal bleeding, endometrial hyperplasia with atypia (Figure 2). The commonest complaint was heavy menstrual bleeding (79\%). 22 Out of 24 women had more than normal sized uterus. Majority, 15(62.5\%) uterus were of 12 weeks size (Table 3). NDVH + BSO done in 7 cases.

In this study, there was bladder injury in one patient who had previous two CS, which was identified and repaired intraoperatively and foley's catheter was kept for 2 weeks. Pelvic collection was seen in 2 patients with average size of $5 \times 5 \mathrm{~cm}$, which was managed conservatively. 3 patients had UTI in the postoperative period, treated with antibiotics and culture report was sterile. 2 patients developed fever in the immediate postoperative period. One patient developed urinary retention on post-operative day 2, same relieved by catherization and catheter was retained for two days and then removed after intermittent clamping.

Mean hospital stay was 5 days. Mean duration of surgery was 60 minutes.

There was no excessive bleeding during the procedure in any of the patients and none of them required blood transfusion during the intraoperative and postoperative period. Postoperative hemoglobin was normal.

\section{DISCUSSION}

Hysterectomy is the most common gynecological surgery. Vaginal hysterectomy is associated with lower complication rates and more rapid recovery. In this study all 24 women underwent non-descent vaginal hysterectomy successfully.

In this study, majority of the women $(41.7 \%)$ were in the age group of $46-49$ years as compared to $48.6 \%$ in the age group of 41-45 years in the study by Mehla et al and $46 \%$ in the age group of $41-45$ years in the study by Zahan et al. ${ }^{3,4}$

In this study, 18 women $(75 \%)$ were para 2 among which 15 women had previous $2 \mathrm{CS}$. Another study by Rameshkumar $\mathrm{R}$ et al, reported previous $2 \mathrm{CS}$ in $53 \%$ of cases. $^{5}$

Most common indication for hysterectomy in this study was fibroid uterus $(41.7 \%)$. Similarly, the most common indication in the study by Saha et al, was fibroid uterus in $46 \%$ cases and also in the study by Kumar et al and $68 \%$ fibroid uterus in the study by Rupali et al, and $43 \%$ in Chandana et al. ${ }^{6-9}$

Dysfunctional uterine bleeding was the common indication in the study by Maiti et al, $(43 \%), 44 \%$ in the study by Zahan et al, and $52 \%$ in the study by Shinde et al. ${ }^{4,10,11}$
In this study, majority 15 (62.5\%) were having 12 weeks sized uterus. In the study by Mehla et al, $71.4 \%$ uteri were less than 8 weeks size. ${ }^{1} 58.3 \%$ uteri less than 8 weeks size in the study by Maiti et al, $68 \%$ uteri less than 10 weeks size in the study by Shanthi et al and $63.3 \%$ uteri were bulky in the study by Rameshkumar. ${ }^{5,10,12}$

In this study, there was bladder injury in one patient. Similarly, one bladder injury in the study by Kumar et al and Chandana et al and two cases of bladder injury in the study by Maiti et al. ${ }^{7,9,10}$ Four women required blood transfusion in the study by Zahan et al and two women in the study by Rupali et al whereas none required blood transfusion in this study. ${ }^{4,8}$ The limitation of this study is the small sample size and is not compared with abdominal hysterectomy.

\section{CONCLUSION}

Vaginal hysterectomy is associated with more rapid recovery and lesser complications. Non-descent vaginal hysterectomy is safe in women with previous CS. Proper preoperative and intraoperative evaluation is important for deciding upon the feasibility of NDVH.

A successful NDVH depends on the expertise and experience of the surgeon. This study concludes that nondescent vaginal hysterectomy can be performed in patients with previous one or two caesarean section with lesser complications and without much difficulty. Hence, non-descent vaginal hysterectomy appears to be feasible, safe and cost-effective alternative to abdominal hysterectomy in women with previous caesarean section

\section{ACKNOWLEDGMENTS}

Authors would like to thank all colleagues and family members for their supports in doing this study.

\section{Funding: No funding sources \\ Conflict of interest: None declared}

Ethical approval: The study was approved by the Institutional Ethics Committee

\section{REFERENCES}

1. Bernstein SJ, McGlynn EA, Siu AL, Roth CP, Sherwood MJ, Keesey JW, et al. The appropriateness of hysterectomy: a comparison of care in seven health plans. JAMA. 1993;269(18):2398-402.

2. Unger JB. Vaginal hysterectomy for the woman with a moderately enlarged uterus weighing 200 to 700 grams. Am J Obstet Gynecol. 1999;180(6):1337-44.

3. Mehla S, Chutani N, Gupta M. Non descend vaginal hysterectomy: personal experience of 105 cases. Int $\mathbf{J}$ Reprod Contracept Obstet Gynecol. 2015;4(1):61-5.

4. Zahan AA, Shahnewaz K, Khan F, Salma U. Non descent vaginal hysterectomy: a rational surgical approach. Bangla J Obstet Gynaecol. 2015;30(1):159. 
5. Kamat L, Dhanlaxmi L, Ramesh Kumar R, Moni S. Non-descent vaginal hysterectomy in previous cesarean section: a retrospective study of 30 cases. Int J Reprod Contracept Obstet Gynecol. 2017;6(7):2772.

6. Saha R, Shrestha NS, Thapa M, Shrestha J, Bajracharya J, Padhye SM. Non-descent vaginal hysterectomy: safety and feasibility. Nepal J Obstet Gynaecol. 2012;7(2):14-6.

7. Kumar N, Tayade S. Role of non-descent vaginal hysterectomy in previous cesarean section scar women. Int J Reprod Contracept Obstet Gynecol. 2015;4:785-9.

8. Rupali D, Shivani A, Manisha MB, Soumendra S. Non descent vaginal hysterectomy: an experience. J Obstet Gynaencol. 2004;54:376-8.

9. Chandana C, Venkatesh S, Shah TN. Non-descent vaginal hysterectomy for benign gynaecological disease-a prospective study. J Evidence Based Med Healthcare. 2014;1(8):827-33.
10. Maiti GD, Pillai A, Jose T, Lele PR. Non-descent vaginal hysterectomy in women with previous caesarean section scar: our experience. Int J Reprod Contracept Obstet Gynecol. 2018;7(6):2405.

11. Shinde S, Aher G, Gavali U. Non descent vaginal hysterectomy (NDVH): our experience at a tertiary care centre. Int J App Basic Med Res. 2015;5(1):1516.

12. Shanthi S, Rani SU, Arumaikannu J. Feasibility of non-descent vaginal hysterectomy (NDVH) in women with scarred uterus-our experience. Pain. 2017;2:8.

Cite this article as: Jacob KJ, Divya MB. Nondescent vaginal hysterectomy in previous cesarean section: a retrospective study. Int J Reprod Contracept Obstet Gynecol 2020;9:3239-42. 